\section{Pricing would limit carbon rebound}

Unilateral national climate policies are not strict enough to control carbon rebound - a side effect of some energyconservation strategies that undercuts net carbon savings. I suggest that a global agreement on variable carbon pricing at the forthcoming climate summit in Paris would reap considerable rebound-related benefits.

Economy-wide studies indicate that overall carbon rebound is at least $50 \%$, depending on the country (J. Dimitropoulos Energy Policy 35, 6354-6363; 2007). Despite this, the effects of rebound have been largely ignored by the Intergovernmental Panel on Climate Change and at United Nations climate meetings.

Technical standards do not control rebound effectively: they cover only a small subset of products. For example, when the European Union began phasing out incandescent light bulbs in 2009, light-emitting diodes became so widespread that any energy savings were reduced.

The most effective way to discourage rebound is through carbon pricing, a policy that underpins all potential energysavings decisions. Any rebound tendency would elicit a higher carbon price under a cap-andtrade permit scheme. A carbon tax would require frequent adjustment to achieve the same outcome. This would be difficult politically, especially in the form of nationally distinct taxes.

Jeroen C. J. M. van den Bergh ICREA, Barcelona; Autonomous University of Barcelona, Spain; and VU University Amsterdam, the Netherlands.

jeroen.bergh@uab.cat

\section{Safeguard the ideas of junior scientists}

Good institutional practice fosters research reproducibility (see C. G. Begley et al. Nature 525, 25-27; 2015). But individuals still have a responsibility to work with their institutes by practising research with integrity.

Scientists are encouraged to be open about their research, which makes unpublished junior scientists particularly vulnerable to intellectual-property theft. This can be a risk when seeking out collaborations, presenting at conferences and submitting manuscripts for review, and even after employment interviews.

We are all subject to the same frailties and pressures, but we are members of a community with a common goal. We cannot always own originality, but we must show respect for it.

Jennifer S. Le Blond Imperial College London, UK.

j.le-blond@imperial.ac.uk

\section{Diesel pollution long under-reported}

The furore over Volkswagen's cheating of US emissions tests (see Nature http://doi.org/723; 2015) prompts a reminder that pollution from diesel vehicles has long been under-reported. This includes nitrogen oxides, hydrocarbons and particulates.

Emissions can be measured across cities using instruments on aircraft and high towers, and for vehicles using numberplate recognition and remote sensing. Modern diesel engines emit roughly four times more nitrogen oxides on average than are recorded in lab tests, which use unrepresentative driving cycles and technical strategies to reduce emissions (D. C. Carslaw and G. Rhys-Tyler Atmos. Envir. 81, 339-347; 2013). Real-world emissions of diesel hydrocarbons exceed estimates used for air-quality planning by up to 70 times (R. E. Dunmore et al. Atmos. Chem. Phys. 15, $9983-$ 9996; 2015).

Particulate matter is estimated to kill 29,000 people each year in the United Kingdom (see go.nature.com/kdzn4r). This figure will rise when the UK Committee on the Medical
Effects of Air Pollutants, which advises government, quantifies the extra health burden associated with nitrogen dioxide.

Improvements in urban air quality stalled a decade ago in many European cities, where nitrogen dioxide often exceeds regulatory standards and global health guidelines. To tighten up diesel-emissions control, tests need to be more accurate, more transparent and regulated more rigorously (see also F. J. Kelly and J. C. Fussell Envir. Geochem. Health 37, 631-649; 2015).

Alastair C. Lewis, David C. Carslaw University of York, UK. Frank J. Kelly King's College London, UK.

ally.lewis@york.ac.uk

\section{Tackling soil loss across Europe}

A European Commission analysis indicates that soil erosion continues to outstrip soil formation across the European Union, but that the Common Agricultural Policy is narrowing the gap (P. Panagos et al. Environ. Sci. Policy 54, 438-447; 2015).

The amount of soil lost to water erosion in Europe equates to an estimated economic loss of about US $\$ 20$ billion per year, based on a replacement cost of $\$ 20$ per tonne. Between 2000 and 2010, intervention measures through the Common Agricultural Policy have reduced the rate of soil loss in the European Union by an average of $9.5 \%$ overall, and by $20 \%$ for arable lands.

Continued monitoring of human-induced changes to soil every $5-10$ years will be crucial for refining soil policies (D. A. Robinson Science 347, 140; 2015).

Panos Panagos, Pasquale

Borrelli European Commission Joint Research Centre - IES, Ispra, Italy.

David A. Robinson NERC Centre for Ecology and Hydrology, Environment Centre Wales, Bangor, UK.

panos.panagos@jrc.ec.europa.eu

\section{Protect biodiversity, not just area}

The Convention on Biological Diversity's Aichi Target 11 mandates that $17 \%$ of terrestrial and $10 \%$ of marine environments be conserved in protected areas by 2020 . Such simple numeric indicators act as motivators and a measure of progress. But striving to meet the stipulated coverage should not compromise the convention's broader goal of maximizing biodiversity.

Area coverage is the only element of Target 11 that is on track, at least on land (D. P. Tittensor et al. Science 346, 241-244; 2014). Other crucial elements are effective, equitable biodiversity management; ecological representation of a mix of ecosystems; and connectivity between sites to allow species dispersal. Some species and ecosystems may be lost if implementation of these elements is delayed much longer.

Focusing on area coverage alone risks creating perverse outcomes. It encourages the proliferation of large protected areas that are under little threat, and neglects areas where protection is most needed (see go.nature.com/o5ny9j and go.nature.com/hi6qn5). If not considered in the context of other elements of Target 11, maximizing the area under protection increases the financial and political cost of meeting the same biodiversity goals. As with other global policy goals (see S. Fukuda-Parr J. Hum. Dev. Capab. 15, 118-131; 2014), the abstract global target has created unintended consequences for national conservation planning.

With negotiations beginning in 2016 for the next tranche of the convention's targets, new incentives are needed to emphasize the pivotal additional elements of Target 11.

Megan Barnes* University of Queensland, St Lucia, Australia. megan.barnes@uq.edu.au ${ }^{*}$ On behalf of 4 correspondents (see go.nature.com/d1vieb for full list). 